Barttomiej Skowron

Contemporary Polish Ontology

De Gruyter Studium 


\section{Philosophische Analyse/Philosophical Analysis}

Editor in Chief

Herbert Hochberg, Rafael Hüntelmann, Christian Kanzian, Richard Schantz, Erwin Tegtmeier 


\section{Contemporary Polish Ontology}

Edited by

Barttomiej Skowron

DE GRUYTER

MOUTON 


\section{Library of Congress Cataloging-in-Publication Data}

A CIP catalog record for this book has been applied for at the Library of Congress.

\section{Bibliographic information published by the Deutsche Nationalbibliothek}

The Deutsche Nationalbibliothek lists this publication in the Deutsche Nationalbibliografie; detailed bibliographic data are available on the Internet at http://dnb.dnb.de.

(c) 2019 Copyright-Text, Walter de Gruyter GmbH, Berlin/Boston

\section{Cover image: Cover-Firma}

Typesetting: le-tex publishing services $\mathrm{GmbH}$, Leipzig

Printing and binding: Druckerei XYZ

(2) Printed on acid-free paper

Printed in Germany

www.degruyter.com 


\section{Contents}

Urszula Wybraniec-Skardowska

Logic Towards Ontology of Language - 1

1 Introduction - 1

1.1 Knowledge-Language-Reality -2

1.2 Logical Conception of Language -5

1.3 The Double Ontological Status of Language Expressions - 6

1.4 Categories of Language Expressions and the Ontic Categories of Objects - 8

2 An Outline of the Formal-Logical Theory of Language - 9

$2.1 \quad$ About the Logical Theory of Language Syntax - 10

2.2 The Foundations of the Formal-Logic Theory of Semantics and Pragmatics of Language - 13

3 About the Ontological Neutrality of Logic -19

Author Index -25 



\title{
Urszula Wybraniec-Skardowska
}

\section{Logic Towards Ontology of Language ${ }^{1}$}

\begin{abstract}
The main purpose of the paper is to outline the formal-logical, general theory of language treated as a particular ontological being. The theory itself is called the ontology of language, because it is motivated by the fact that the language plays a special role: it reflects ontology and ontology reflects the world. Language expressions are considered to have a double ontological status. They are understood as either concretes, that is tokens - material, physical objects, or types classes of tokens, which are abstract objects. Such a duality is taken into account in the presented logical theory of syntax, semantics and pragmatics. We point to the possibility of building it on two different levels; one which stems from concretes, language tokens of expressions, whereas the other one - from their classes, types conceived as abstract, ideal beings. The aim of this work is not only to outline this theory as taking into account the functional approach to language, with respect to the dual ontological nature of its expressions, but also to show that the logic based on it is ontologically neutral in the sense that it abstracts from accepting some existential assumptions, related with the ontological nature of these linguistic expressions and their extra-linguistic ontological counterparts (objects).
\end{abstract}

Keywords: formal logic, ontology, ontology of language, syntax, expression-token, expression-type, semantics, meaning, denotation, ontic category.

\section{Introduction}

This section has a preliminary character. It discusses the main aspects and concepts related to the descriptive, representative and referential function of language, and the dual ontological nature of its expressions due to certain assumptions and logical foundations. The theory of the language so approached is outlined in the main part of the paper (Section 2), and some summary results and conclusions are included in Section 3.

1 This article is a modified version of the work entitled Logiczna koncepcja języka wobec zatożen egzystencjalnych [The logical conception of language towards existential assumptions], dedicated to Professor Jacek J. Jadacki on his $70^{\text {th }}$ birthday, Wybraniec-Skardowska 2017.

Urszula Wybraniec-Skardowska, Department of Philosophy, Cardinal Stefan Wyszyński University, Warsaw, Poland. 


\subsection{Knowledge-Language-Reality}

This section introduces us to the issue of linguistic adequacy related to the function of language as the ontological being used on the one hand to describe the world (that is what the ontology deals with as the theory of being), as well as a being to represent our knowledge about this world. In this section I justify why the theory of language must be an ontological theory. I also argue in favor of the logical conception of language.

For the most general definition of ontology, we shall refer to the definition proposed by Perzanowski.

Ontology is the general theory of possiblity, i.e. the realm of all possibilities - the ontological space. Metaphysics, on the other hand, is an ontology of the world, i.e. the reality of all existing items, called facts. [...] Real philosophy, however, is about being. (Perzanowski, 2012, p. 45)

By being we understand here everything that exists, that can exist, that is not contradictory in itself. The task of ontology - as we understand it here - is to describe the structure of being or reality. Language (which is a tool of building the theory of being at the same time) serves this description.

Studies on language are helpful in producing this description. For language to be able to perform this - one of the basic - functions of language: a faithful description of the reality and its structure, there must follow a peculiar compatibility between the elements of the following triad:

\section{Language - Knowledge - Reality,}

which I call in brief language adequacy, described in a theory of language.

Language serves to represent human knowledge acquired in the process of cognition of reality. It is simultaneously a means of describing the cognized reality. Operating with language by means of logic and thinking allows transforming and enriching knowledge in order to better get to know and discover the world. It is thus also a tool of expanding the cognition of the reality on the basis of the already possessed knowledge, not only ontological by the way.

In order that language could fulfil its descriptive function, it should reflect the structure of being, the reality, with its own structure. The structure of language undoubtedly is connected with that of the cognized world. It is conditioned by the formation of knowledge obtained in the process of cognizing the reality, framing the structure of this reality. This structure is described, as we know, by ontology. Knowledge of the structure of the reality allows to uniformly speak about the world, making inter-human communication more effective. 
Relevant components of knowledge correspond to the elements composing the reality. In language, we speak about both the former and the latter by means of its expressions. They have their counterparts in language, in its components, in its expressions. The components of the reality belong to suitable ontological categories, components of knowledge - to appropriate categories of components of knowledge, whereas components of language - to suitable syntactic categories as well as semantic categories, that is to defined categories of language expressions. Language of such expressions serves to faithfully describe the world and the given domain of knowledge.

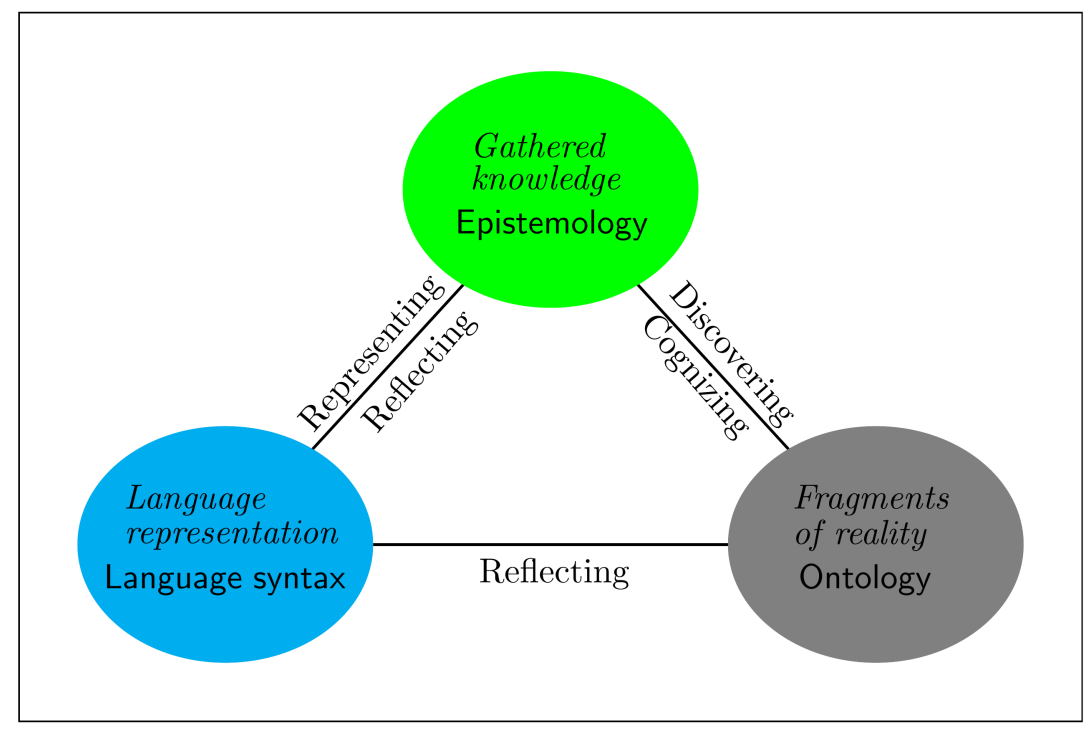

Diagram 1

Language adequacy is achieved when language syntax reflects its bi-aspectual semantics in a faithful way - therefore on the one hand - the existing fragments of cognized or discovered reality (extensional semantics), and - on the other one - the gathered knowledge which is a result of their cognition or discovering (intensional semantics) (see Diagram 1). Language should thus be a reflection of a determined section of the reality and - at the same time - a reflection of the knowledge about it, knowledge which has been gathered and is being expanded. 
As it can be seen, language and its syntax are connected with both the ontology of the world, that is with everything that exists and with epistemology which deals with cognition of the world, the result of which is the gathered knowledge.

Since language exerts such a considerable impact on ontology, it becomes vital to work out a general theory of language, language as a particular ontological being. This theory is called ontology of language. By means of metalanguage it describes the structure of language and its properties.

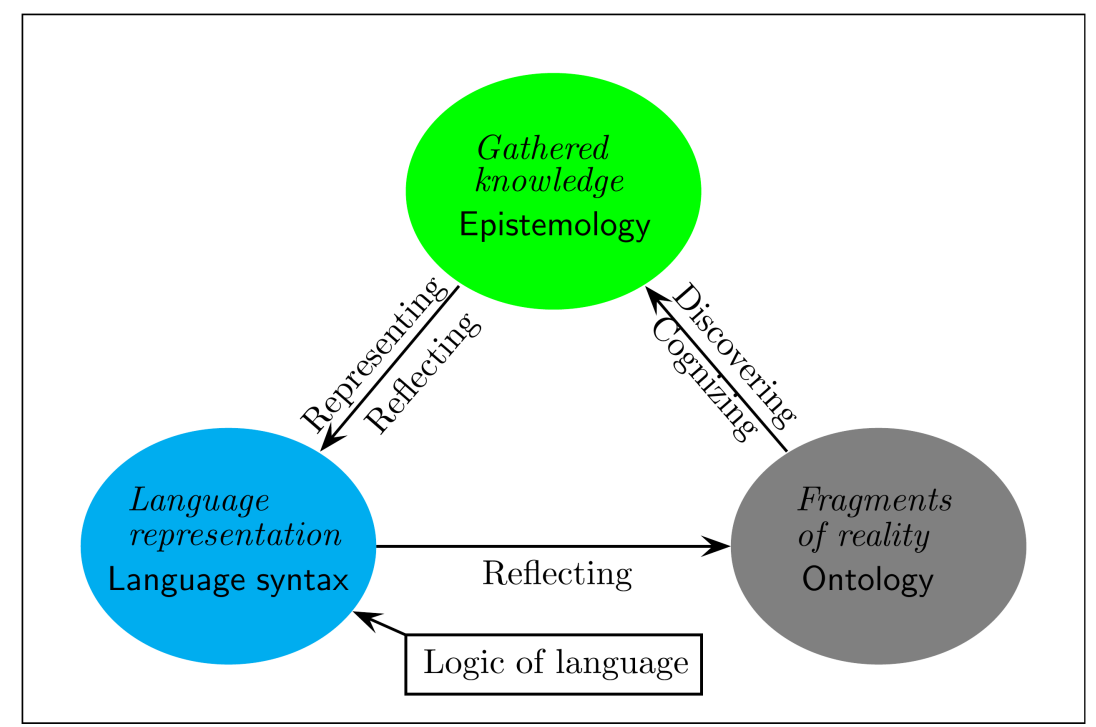

\section{Diagram 2}

In the same way as there exist a great number of conceptions of being, so there exist plenty of conceptions of language and many theories of language. Here, the conception of language in the framework proposed by Ajdukiewicz (1974, p. 12,13) will be of interest to us, and the logical theory of language (logical semiotics) formalized on the ground of classical formal logic and set theory will be the theory built according to this conception (see Diagram 2). Its assumptions are presented below. 


\subsection{Logical Conception of Language}

In Ajdukiewicz's framework (Ajdukiewicz, 1974, p. 13, note 6), the logical concept of language assumed that "in order to describe a language we have (i) to list its expressions, and (ii) univocally to assign specified meanings to these expressions." Ajdukiewicz (1974, p. 13) wrote also that

By drawing attention to the difference between the logical concept of language and those concepts of language which are being used by linguists we wish to emphasize that the logical concept of language is much simpler than the linguistic one, and that its analysis prepares that set of concepts which is indispensable to give clarity to the research done by linguists.

The Ajdukiewicz's logical notion of language is included in the logical conception of language explaining how on the basis of logic is understood language. It is conceived in it as a system of conventional signs. In compliance with the logical conception of language, the following are the basic elements which form the language (as a system of signs):

1. vocabulary,

2. rules of syntax:

(a) qualifying - settling down which objetcs qualify as simple expressions (words) of the vocabulary;

(b) constructive - determining how to form other signs from simpler signs complex expressions of language,

3. semantic rules: settling down what the signs: a) mean, b) designate, and denote,

4. pragmatic rules: determining the relations between signs of language and its users in the process of communicating and cognizing the reality.

Language, in the logical conception, is an ideal creation. All the known real languages are "logically defected". Language, in the logical conception, is an idealizing reconstruction of real languages and constitutes a subject of formal-logical description in the present work, which - as a matter of fact - does not apply to languages which are normally used. The formal-logic theory of language sketched further (in Section 2), frames problems pertaining to the foundations of the theory of language in a possibly general way, narrowing the problem area, yet providing a simple apparatus of notions and solving questions which are connected with the ontological nature of language expressions, their meaning (intension) and denotation (extension). Solving these problems, the theory is based on different assumptions, including certain existential ones, which are not satisfied in full 
by authentic languages, since real conditions in which they function most often depend on extra-language factors and are not entirely neutral.

Language that is characterized according to logical conception is one of wordssigns - expressions built in compliance with the rules of syntax, the so-called well-formed expressions - having one meaning and one denotation assigned to them, performing - at the same time - the function of representing the gathered knowledge about the cognized reality, as well as playing the role of an intermediary in the process of transferring and exchange of information. Because language as an ontological being consists of expressions, and their ontological nature can be of two kinds, the theoretical considerations over language must include certain initial assumptions regarding the ontological status of expressions of that language. The problem will be discussed in the following subsection of the work.

\subsection{The Double Ontological Status of Language Expressions}

What is the ontological status of expressions, language objects? The question about the ontological status of these objects comes down to the following two polar (yes-no) questions:

1) Are language objects, including words, expressions - concrete, real objects of a defined shape, extended in time and space?

2) Are language objects, including words, expressions - abstract objects or certain ideal beings?

The ontological status of language objects which concern the above-mentioned questions is different: they belong to two different ontological types. In the semioticlogical practice we use them in an equal manner.

Most often, in compliance with the differentiation made by Peirce (1931-1935, sec. 4.537), inscriptions, words or expressions are understood as either concretes, that is tokens (events) - material objects perceivable through senses, or types classes of uniform, identifiable (in a broad sense) tokens, which can be concern as abstract objects. Such a duality in the understanding of a language inscription appeared in the famous monograph by Tarski (1933, pp. 5, 6, note: 5, p. 24, note 19; 1956, p. 156, note: 1, p. 173: note 1) and gained popularity especially thanks to works by R. Carnap in the 1940s (see Carnap 1942, sec. 3: Sign-Events and Sign-Designs).

Expressions which perform the function of representing gathered knowledge about the cognized reality and the role of intermediary in the process of transferring and exchanging information, are signs-tokens, specimens of signs-types, that is 
classes of signs-tokens, in some respect identifiable, e.g., equiform. ${ }^{2}$ The meaning and denotation are assigned, on the other hand, only to expressions-types, which - in contrast to their tokens, being their physical representations, thus objectsconcretes (e.g., inscriptions or sounds) - are objects-abstracts. ${ }^{3}$ Here, it needs to be said immediately that although in the logical semantics, explanation of the notions 'meaning' and 'denotation' requires using expressions-types, in the very defining of the these notions itself it is expressions-tokens which are used.

We come to deal with the double ontological character of language expressions also when we take into account the so-called functional approach to language in the framework proposed by Jerzy Pelc (1979). Then we take into consideration two manners of usage of expressions. Regarding the first of them, the manner of usage (use) takes place solely in defined conditions, in determined languagesituational contexts and concerns expressions-tokens, whereas in the case of the other - the manner of usage ( $\underline{\text { use }}$ ) characterizes the meaning of an expression as an expression-type seen in isolation from the situational-context, e.g., applied as an entry in a dictionary edited in the traditional book form.

The logical theory of language should thus assume the existence of both expressions-tokens (language-based concretes) and expressions-types (languagebased abstracts). The dual ontological character of language objects and using them in a double manner point to the necessity of bi-aspectual characterizing of language in the theoretical logical conception of language: as language of expressions-tokens and as that of expressions-types.

Elaboration of a defined theory of language cannot at the same time remain without an influence on the two main currents of language ontology related to two fundamental ideas which took their shapes in the controversy on universals: nominalism and realism.

Taking the nominalistic and concretistic position, it is assumed that the basic plane of language are expressions-tokens, therefore concretes. Abstract expressions, that is types of expressions, are then constructs of secondary analysis. On the other hand, assuming that the basis of studies on language are ideal objects, abstracts understood as types of expressions, while expressions-tokens, available thanks to cognition through senses, are constructs of secondary analysis, we opt for the platonizing standpoint.

Building a formal-logical theory of language syntax (Section 2.1), we have to determine, though, whether the primary language beings are signs-concretes

2 Equiformity is treated here as cum grano salis (Jadacki, 1997). Carnap (1934) called the relation: syntactical equality (see translation in 2001, p.15).

3 The differentiation between sign-token and sign-type was introduced into semiotics by Peirce (1906, pp. 506, 512; 1931-35, CP 4.537; 1998, pp. 125, 480, 488). 
and the secondary ones - signs-abstracts, or the other way round. In this way, questions of the theoretical logic of language intertwine with the problem area of the philosophical nature, especially ontological ones. This concerns not only the logical syntax of language, but also its logical semantics and pragmatics, as well as the very problem of language adequacy of knowledge itself in relation to the reality.

The notions which are introduced and made precise within the sections of logical theory of language must have their existence secured, guaranteed by relevant axioms and definitions. However, should logic settle anything as regards the existence of extra-language entities, which language expressions relate to? To this question, we try to give some answer further (Section 2.2), before discussing what the categories of language expressions are and what are the categories of their extra-linguistic counterparts.

\subsection{Categories of Language Expressions and the Ontic Categories of Objects}

The general notion of categories, which was constructed by Jadacki (see Jadacki, 2003, pp. $109 \mathrm{ff}$ ) as a predicative subset of an established set, allows speaking about both language categories (distinguished in the set of expressions) and ontic categories (distinguished in the set of objects).

Language expressions, performing determined syntactic functions and built according to the rules of language syntax (that is well-formed expressions), are included in appropriate syntactic categories. Speaking freely, expressions playing the same role in construction of complex expressions also belong to the same category. When we abandon the purely syntactic point of view on expressions and take into account their semantic counterparts (components of knowledge) or their objective counterparts - beings which the expressions relate to, or those which the expressions denote, then these expressions are included in appropriate semantic categories, respectively: intensional or extensional. The compatibility of suitable syntactic and semantic categories of language expressions is an indispensable condition of language adequacy of knowledge in relation to the cognized reality (Wybraniec-Skardowska, 2015, sec. 4). This compatibility entails compliance of language categories with suitable ontological categories which include the extra-language counterparts of language expressions. It is related to the accepted ontology. We embark on the ground of ontology, taking into account exclusively the substantive counterparts of expressions of language categories, thus 
extra-language objects, beings. ${ }^{4}$ These objects are qualified into appropriate ontic categories. The types of these categories are established in an ontology. Depending on the determined ontological conception, there is one or there are a few ontic categories which are distinguished. And thus, the following ones can be the ontic categories: the category of individuals, sets of individuals, properties, relations (in particular one-argument or many-argument operations-functions), periods, areas, states of affairs. Distinguishing these or other ontic categories is obviously associated with which beings we attribute existence to that can be real or not, e.g., intentional or ideal. ${ }^{5}$

Further, presenting some semantic foundations of the formal-logical theory of language (Section 2.2.), we shall accept the postulate of "democratic nature of beings": all beings are equally empowered, are treated in the same way when it comes to existence and deciding something about them.

\section{An Outline of the Formal-Logical Theory of Language}

The formal-logical considerations concern syntax and bi-aspectual, intensional and extensional semantics of language characterized categorially in the spirit of the theory of syntactic categories of Leśniewski-Ajdukiewicz (see Leśniewski $(1929,1930)$ and Ajdukiewicz $(1935,1960))$ and in compliance with the ontological canons of Frege (1892, pp. 31-36, 36-38; 1997, pp. 155-159, 159-171), as well as with the motto of Bocheński (1949): syntax mirrors ontology and some ideas of Suszko (1958, 1960, 1964, 1968): language is supposed to be a linguistic schema of the ontological reality and - at the same time - a tool of its cognition. The theory of language outlined here frames the development and some explication of the ideas given in the works by the above-mentioned authors. ${ }^{6}$ In Section 2.1 we outline the

\footnotetext{
4 It can be accepted, following Jadacki (1992), that everything that has at least one property vested (the relation of vesting is a binary relation here, whose domain is a set of properties and the counter-domain - just a set of objects; the relation of vesting is then probably a primitive notion of ontology) is an object (an entity). It can also be assumed, following Eukasiewicz, that everything that both can have and cannot have certain property, that is non-contradictory, is an object.

5 See Ajdukiewicz (1949-1950), Bocheński (1974), Augustynek \& Jadacki (1993).

6 This theory is built over classical logic and set theory. Its outline is based on the notions which were presented in my works (Wybraniec-Skardowska, 1991, 2006, 2007, 2009, 2015). Tokens of language expressions are represented by the following variables: $e, e^{\prime}, e_{1}, e_{2}, \ldots$ whereas types of such expressions by the variables: $t, t^{\prime}, t_{1}, t_{2}, \ldots$
} 
logical theory of syntax of language, and in Section 2.2 its extension to the theory of semantics and pragmatics of the language.

\subsection{About the Logical Theory of Language Syntax}

Each language can be more or less adequately described with the use of a defined grammar. In the Polish tradition it is categorial grammar which serves the purpose of such a description. It derives from Kazimierz Ajdukiewicz $(1935,1960)$ and grew under the influence of Husserl's idea of pure grammar (Husserl, 1900, 1901), as well as Leśniewski's theory of semantic/syntactic categories (Leśniewski, 1929, 1930).

Logical syntax of any language $L$ is characterized formally on two dual levels: on one of them it concerns the language of expressions-tokens, on the other one that of expressions-types. Accepting the view that expressions-concretes, that is expressions-tokens - thus, physical objects are the fundamental language layer, whereas the secondary layer for $L$ are expressions-abstracts, that is expressionstypes - thus, ideal objects, it is the concretistic philosophical view on the nature of language entities that is adhered to (it was held, among others, by Leśniewski). Supporting the view that expression-types are the basic language layer, while expressions-concretes are the secondary one, we take the opposite standpoint - a platonizing one.

2.1.1. In the first case, on the level of tokens, language $L$ is generated in the most general way by grammar:

$$
G=\left\langle U_{L}, \sim, c, V, \varrho, E ; S\right\rangle \text {, where }
$$

$U_{L}$ is a non-empty universum of all signs-tokens of $L$,

$\sim$ - two-argument relation of identifiability of signs of universum $U_{L}$,

$V$ - vocabulary of words-tokens of language $L$,

$c$ - three-argument relation of concatenation defined in $U_{L}$,

$\varrho-n$-argument relation of forming complex expressions-tokens $(n>1)$,

$E$ - the smallest set of all expressions-tokens containing $V$ and closed under the relation $\varrho$,

$S \quad$ - set of all well-formed expressions-tokens of language $L$.

The notions $U_{L}, \sim, V, c, \varrho$, are primitive notions of the theory characterized axiomatically. When $G$ is a classical categorial grammar, each expression-token $e$ of set $S$ has a categorial index $i(e)$ of some non-empty set $I$ assigned in an unambiguous way, and each complex expression of set $S$ is built on the functor-argument 
basis so that it is possible to distinguish in it a constituent, the so-called functor, which - together with the remaining constituents of that expression, called arguments of the functor, forms this expression; the notion of the constituent of a complex expression is defined inductively. Categorial indexes serve to establish the syntactical role of expressions and to examine their syntactic connection, though not only. Set $S$ is formally defined as the smallest set of expressions, containing vocabulary $V$ and closed with respect to relations connected with Ajdukiewicz's principle of syntactic connection. All the sets and relations of system $G$ are non-empty sets. Hence, the resulting primary existence of expressions-tokens in particular.

On the second level - the level of types of expressions, language $L$ is characterized through the system of notions which is dual to system $G$ :

$$
\underline{G}=\left\langle\underline{U}_{L},=, \underline{c}, \underline{V}, \underline{\underline{e}}, \underline{E} ; \underline{S}\right\rangle \text {, where }
$$

$\underline{U}_{L}$ is a set of all language signs-types of language $L$,

$=-$ relation of common identity of signs of universum $\underline{U}_{L}$,

$\underline{V}$ - vocabulary of words-types of language $L$,

$\underline{c}$ - relation of concatenation defined on types of signs of $\underline{U}_{L}$,

$\underline{Q}$ - relation of forming complex expressions-types,

$\underline{E}-$ set of all expressions-types of language $L$,

$\underline{S}$ - set of all well-formed expressions-types of language $L$.

All the notions of grammar $\underline{G}$ are derivative constructs, defined by means of dual notions of grammar $G$. Any set $\underline{Z}$ of types of system $\underline{G}$ is a quotient set of set $Z$ of tokens of the first level due to the relation of identifiability $\sim$, i.e.,

$$
\underline{Z}=Z / \sim \text {. }
$$

Thus, any set $\underline{Z}$ of types of expressions is composed of equivalence classes of tokens of set $Z$, i.e.,

$$
t \in \underline{Z} \Leftrightarrow \exists e \in Z\left(t=[e]_{\sim}=\left\{e^{\prime} \in Z \mid e^{\prime} \sim e\right\}\right) .
$$

The relation of concatenation $\underline{c}$ on types of signs is defined by means of the relation of concatenation $c$ on tokens of signs of language $L$ :

$$
\underline{c}\left(t_{1}, t_{2} ; t\right) \Leftrightarrow \exists e_{1}, e_{2}, e \in U_{J}\left(t_{1}=\left[e_{1}\right]_{\sim}, t_{2}=\left[e_{2}\right]_{\sim}, t=\left[c\left(e_{1}, e_{2} ; e\right)\right]_{\sim}\right) .
$$

Concatenation relation $\underline{c}$ is a two-argument function on types of signs of language $L$.

It is proved that each dual counterpart of the thesis of the syntax theory built first on the level of concretes is a thesis of this theory developed on the level of types, on the second level of formalization of the syntax of language $L$.

The concretistic approach to the formal-logical theory of the syntax of language $L$ was presented in my works (Wybraniec-Skardowska, 1991, 2006). 
2.1.2. The opposite standpoint - the platonizing one - is founded on the assumption that types of signs of language $L$ are ideal signs, independent and objective beings, and are primary in relation to language tokens which are their representatives. The primitive notions of the syntax theory are thus the following notions of system $\underline{G}$ : $\underline{U}_{L}, \underline{c}, \underline{V}$. The other notions of this system are defined then. Obviously, the axiom stating the existence of signs-types, assuming that any type $t$ is a non-empty set, is then accepted.

On the other level of formalization, the level of tokens, there are tokens of signs of language $L$ introduced through axioms and definitions:

(1) $e_{1} \in t_{1} \wedge e_{1} \in t_{2} \Rightarrow t_{1}=t_{2}$,

(2) $e \in U_{L} \Leftrightarrow \exists t \in \underline{U}_{L}(e \in t)$.

The above definition (2) can be considered under the general schema of the definition of subsets $Z$ of set $U_{L}$ :

(DZ) $e \in Z \Leftrightarrow \exists t \in \underline{Z}(e \in t)$.

The relations of identifiability is defined as follows:

$\left(\mathrm{D}_{\sim}\right) e \sim e^{\prime} \Leftrightarrow \exists t \in \underline{U}_{L}\left(e, e^{\prime} \in t\right)$.

The relation of concatenation on tokens of signs is determined by the following definition:

(Dc) $c\left(e_{1}, e_{2} ; e\right) \Leftrightarrow \exists t_{1}, t_{2}, t \in \underline{U}_{L}\left(e_{1} \in t_{1}, e_{2} \in t_{2}, e \in t \wedge \underline{c}\left(t_{1}, t_{2} ; t\right)\right)$.

In a similar way we determine relation $\varrho$.

It is proved that each dual counterpart of the thesis of the syntax theory built - first - on the level of types is a thesis of this theory on the second level of its formalization, that is on the level of tokens.

2.1.3. The two dual approaches towards the two-level syntax theory of language, which are given in Subsections 2.1.1 and 2.1.2 are logically equivalent (see Wybraniec-Skardowska, 1988). In the scope of the language syntax, both conceptions deriving from two different existential assumptions are equivalent. This statement is of a philosophical significance, since it proves that 
In theoretical syntactic considerations on language, the assumption of the existence of abstract language beings can be neglected. ${ }^{7}$

\subsection{The Foundations of the Formal-Logic Theory of Semantics and Pragmatics of Language}

2.2.1. The logical syntax theory allows us to determine sets $S$ and $\underline{S}$ of all the wellformed expressions of language $L$. Its characteristics, being in agreement with the logical conception, requires an unambiguous assignment of meanings to its expressions.

It is only an efficient, precise and clear language which becomes a tool to describe the world, enabling us to aptly transfer information and communicate about the reality. The expressiveness of language consists specifically in unambiguity of its expressions, both as regards their structure and the meaning (intension) and denotation (extension). The syntactic and semantic unambiguity of language expressions is the output condition of its logical meaningfulness. It entails categorial compatibility of language, which is different from that mentioned earlier, that is the compatibility of syntactic categories of language expressions with its semantic categories: semantic (intensional) and denotational (extensional). This compatibility, in turn, entails the syntactic and semantic structural compatibility of language, described in the form of three principles of compositionality of complex language expressions, mutually corresponding to one another: one syntactic and two semantic: the compositionality of meaning and the compositionality of denotation.

However, since unambiguity is such an important factor of language adequacy, it needs first of all establishing what the meaning of the composed expressions of language $L$ is and what this unambiguity of its expressions consists in.

There exist quite a number of conceptions relating to the nature of meaning and different theories of this notion in the literature dealing with philosophy of language. So far none of them has been commonly accepted, though. Also, none of them is a general theoretical conception. Such a conception is sketched in my work (Wybraniec-Skardowska, 2007) and I am going to make reference to it in this part of the present article.

7 The proof of this theorem (see Wybraniec-Skardowska, 1988, 1989) is however based on the regular Platonic set theory. The applied formalism is not thus, in fact, ontologically neutral. This remark was formulated by Jerzy Perzanowski. 
2.2.2. Since the time of Frege the notion of 'meaning' has been differentiated from that of 'denotation'. Frege (1892, p. 31; 1997, p. 156) did distinguish, respectively, Sinn (English: intension) and Bedeutung (English: extension), and we owe the distinction intension-extension to Carnap (1947, Ch.I, sec. 5, sec. 6, pp. 26, 27; sec. 9 , pp. 40-41). On the other hand, the literature devoted to linguistics and semiotics does not always differentiate the two notions.

The notions 'meaning' and 'denotation' are used with reference to expressionstypes of language $L$. They are "assignments" of meanings and denotations to these expressions, respectively. As such they are operations (functions) on expressions of set $\underline{S}$, yet not on all the expressions of the set, but on their non-empty sub-types, that is elements of the set:

$$
\underline{S}^{\star}=\left\{t^{\prime} \subseteq t \mid t^{\prime} \neq \emptyset \wedge t \in \underline{S}\right\}
$$

that is on any non-empty sets of identifiable expressions-tokens of set $S$.

We define these operations, making use of any ideas connected with the understanding of the notion of 'meaning' by Ajdukiewicz $(1931,1934)$ and Wittgenstein (1953, third edition 1967, paragraphs: 20, 349, 421-2, 508, p. 184, 190), as manner of usage of an expression. In order to be able to determine what being the use of an expression is we have to refer to certain semantic-pragmatic notions.

2.2.3. We enrich, thus, the theory of syntax of language $L$ with new primitive notions: set User of all users of language $L$, set Ont of all extra-language objects which expressions of language $L$ relate to, and also the two-argument operation use of using expressions-tokens of language $L$.

The sets User and Ont are conceived in a very broad way. Set User can consist not only of current users of language $L$, but also those of the past and future ones. Nothing is assumed about the ontological nature and the existence of objects of set Ont. They may be concretes, abstracts, ideal, intentional (quasi-objects), fictional objects, etc. It is merely assumed axiomatically about these objects that they are non-empty sets. Nothing is assumed about the ontic categorization of set Ont; the ontic categories can - but do not have to - be the following: category of individuals satisfying certain properties, categories of various relations and functions, category of states of things, and the like.

Relation use of usage of expressions-tokens is also conceived most broadly, e.g., as an operation of invoking, exposing and forming expressions-tokens to indicate appropriate objects of set Ont. Operation use is also called a function of objective reference of expressions-tokens by users of language $L$. This function can also be conceived as a set of all physical activities of users of language $L$, which were, are or will still be activities used in determined situations with the aim to refer concrete tokens of language $L$ to objects of set Ont. It is axiomatically assumed 
about function use that it is a set-theory function, partially mapping Cartesian product User $\times S$ into set Ont, whose first domain is the whole set User, while the other one - proper subset of set $S$ of expressions-tokens.

We read the expression $u s e(u, e)=p$, where $u \in U s e r, e \in S$ and $p \in$ Ont, as follows: user $u$ uses expression-token $e$ with reference to object $p$. When $u s e(u, e)=$ $p$ takes place, then object $p$, is called object reference of token $e$ indicated by user $u$ of language $L$. We say about expression $e$ that it has object reference when it is used by a user with reference to any object. Two expressions-tokens have - at the same time - the same manner of usage use, when they have the same object reference.

Relation $\underline{\text { use }}$ of using expressions-types is determined by means of operation use of using tokens of expressions. It is axiomatically assumed about it that it is a non-empty relation defined on Cartesian product User $\times S^{\star}$ and is defined by the formula:

D0. $u \underline{\text { use }} t \Leftrightarrow \exists e \in t \exists p \in$ Ont $(u s e(u, e)=p)$.

It follows from the accepted assumptions or definitions that each user of language $L$ uses at least one expression-token with reference to any object, and hence uses at least one expression-type of set $\underline{S}^{\star}$.

Defining the meaning of expression-type as a common way of using types of expressions, requires introducing the notion of relation $\approx$ the same manner of usage of these expressions. In the definition of this relation, however, it is needed to employ the notion use of using expressions-tokens.

2.2.4. The formal definition of relation $\approx$ is introduced in the following way:

D1. $t \approx t^{\prime} \Leftrightarrow \forall u \in U \operatorname{User}\left[\left(u \underline{u s e} t \Leftrightarrow u \underline{u s e} t^{\prime}\right) \wedge \forall p \in \operatorname{Ont}(\exists e \in t(u s e(u, e)=p) \Leftrightarrow\right.$ $\left.\left.\exists e^{\prime} \in t^{\prime}\left(u s e\left(u, e^{\prime}\right)=p\right)\right)\right]$.

In accordance with definition D1, two expressions-types have the same manner of usage use if and only if each user of language $L$ uses in the sense of use one of them only if he uses the other of them, as well as he uses in the sense of use a token of one of them with reference to any object if only he uses a token of the other of them with reference to the same object.

For instance, the word "rain" and the expression "an atmospheric fall in the form of drops of water falling down from a cloud" have the same manner of usage use. Similarly, the expression "a public concert" and the expression "a public performance of pieces of music" have the same manner of usage $\underline{\text { use. }}$. 
It can easily be determined that if two expressions-types have the same manner of usage $\approx$, then there exist tokens of one and the other of them, respectively, which have the same manner of usage in the sense of use.

2.2.5. Relation $\approx$ of having the same manner of usage of types of expressions is an equivalence relation in set $\underline{S}^{\star}$ of expressions-types. Operation $m$ of assigning $a$ meaning to these expressions can thus be defined as the function:

D2. $m: \underline{S}^{\star} \rightarrow 2 \underline{S}^{\star}$, where $m(t)=[t]_{\approx} \quad$ for any $t \in \underline{S}^{\star}$.

Thus, the meaning $m(t)$ of expression-type $t$ is the equivalence class of relation $\approx$ of possessing the same manner of usage of types determined by type $t$. Intuitively, it may be conceived as the common property of all expressions-types having the same manner of usage as $t$. It is this property which is called the manner of usage of expression-type $t$.

Meaning $m(t)$ of expression-type $t$ is thus an abstract being (a non-empty set), whose existence is guaranteed by set theory.

2.2.6. In Ajdukiewicz's logical concept of language, each of its expressions is to have an unambiguously assigned meaning. Type $t$ may, however, include subtypes, the meaning of which differs from the global meaning $m(t)$ defined by definition D2. For instance, the subtype "key" ${ }^{1 "}$ of the expression-type "key", composed only of the identifiable tokens of the expression-type "key", whose object references are music clefs, has the meaning which differs from the global meaning of the word "key", which does not have an unambiguously assigned meaning.

D3. Expression-type thas a meaning assigned unambiguously $\Leftrightarrow$ no proper subtype of expression $t$ has the meaning that differs from the meaning of expression $t$, i.e., symbolically:

$$
\neg \exists t^{\prime} \subseteq t\left(t^{\prime} \neq t \wedge m\left(t^{\prime}\right) \neq m(t)\right) \text {, i.e. } \forall t^{\prime} \subseteq t\left(m\left(t^{\prime}\right)=m(t)\right) .
$$

2.2.7. Expression-type possessing in language $L$ unambiguously assigned meaning should be an unambiguous expression of this language. A formal definition of an unambiguous expression is introduced by means of the notion of denotation which makes reference to that of designating objects of set Ont by types of expressions of language $L$.

D4. $t$ designates $p \Leftrightarrow \exists u \in U \operatorname{User} \exists e \in t(u \operatorname{se}(u, e)=p)$, where $p \in$ Ont.

Thus, expression-type $t \in \underline{S}^{\star}$ designates an object $p$ iff at least one user of language $L$ uses any token of expression $t$ with reference to the object $p$. 
By way of example, the word "laptop" designates each laptop, and the expression "intention" - each intention.

Objects designated by an expression-type are called denotata of this expression. When the denotata of such an expression are objects-concretes (things, persons, etc.), ${ }^{8}$ then we call them designates of this expression.

We call denotation $d(t)$ of expression-type $t$ the set of all its denotata. Formally, $d(t)$ is a value of denotation function $d$ defined in the following way:

D5. $d: \underline{S}^{\star} \rightarrow 2^{\text {Ont }}$ and $d(t)=\{p \in$ Ont $\mid t$ designates $p\}$, for any $t \in \underline{S}^{\star}$.

It follows from the accepted assumptions or definitions that each expression-type which is used by someone in the sense use has (denotes) a non-empty denotation (a set of denotata), therefore designates an object of set Ont. If, therefore, we speak about the so-called empty names to have an empty denotation, we mean that the set of designates (concretes) is an empty set then. Such names are not used by users in the sense $\underline{\text { use }}$ then, since their tokens do not make reference to any object (material, physical); set Ont, according to them, consists of exclusively real concretes.

It needs remarking, too, that not every well-formed expression-type has a non-empty denotation. For instance, the expression "the ceiling writes hot ice" is a syntactically correct one, but as a semantic nonsense is not used and has no denotatum. Let us also notice that subtypes of a given expression-type can have a different denotation which is 'smaller' than the expression itself does.

Let us give two theorems resulting from definitions D5 and D4, as well as theorems of algebra of sets:

T1. If $t^{\prime}$ is a subtype of expression-type $t$ (i.e., $t^{\prime} \subseteq t$ ), then $d\left(t^{\prime}\right) \subseteq d(t)$.

T2. If $t_{1}, t_{2}$ are subtypes of expression-type $t$ and $t=t_{1} \cup t_{2}$, then $d(t)=d\left(t_{1}\right) \cup d\left(t_{2}\right) .^{9}$

It can also be proved that the denotation of the sum of a finite number of subtypes forming the given type is the sum of denotations of these subtypes.

2.2.8. Relations between meaning, unambiguity and denotation are given in the theorems below.

The basic relation between meaning and denotation is described by the following theorem (cf. Wybraniec-Skardowska, 2007, pp. 127-128):

8 We think here about concretes really existing, since one can also speak about non-existing concretes (e.g., thought-based; see Jadacki, 1992).

9 The proof of this theorem is given in the Appendix, at the end of this article. 
T3. $m(t)=m\left(t^{\prime}\right) \Rightarrow d(t)=d\left(t^{\prime}\right), \quad$ for any $t, t^{\prime} \in \underline{S}^{\star}$.

According to T3, two expressions-types have the same denotation when they have the same meaning, therefore if the denotations of these expressions are different, their meanings differ as well.

The theorem which is converse to T3 is not true, since, e.g., the expressions "an equilateral triangle" and "an equiangular triangle" have the same denotation, yet different meanings.

The notion of an unambiguous (having one meaning) expression is introduced by means of the following definition:

D6a. $t$ is unambiguous $\Leftrightarrow \neg \exists t^{\prime} \subseteq t\left(d\left(t \backslash t^{\prime}\right) \neq \emptyset \wedge d\left(t^{\prime}\right) \cap d\left(t \backslash t^{\prime}\right)=\emptyset\right)$, i.e. $\left.\forall t^{\prime} \subseteq t\left(d\left(t \backslash t^{\prime}\right)=\emptyset \vee d\left(t^{\prime}\right) \cap d\left(t \backslash t^{\prime}\right) \neq \emptyset\right)\right)$.

D6b. $t$ is ambiguous $\Leftrightarrow t$ is not unambiguous.

Thus, an expression-type $t$ is unambiguous iff there does not exist such a subtype of $t$ which should have any common denotatum with a non-empty denotation of the difference between the expression $t$ and this subtype; ${ }^{10}$ when such a subtype does exist, expression $t$ is ambiguous.

By way of an example: the expression "a key" is ambiguous, since its subtype "a key ${ }^{2}$ ", designating only keys to open doors, does not have common denotata with the denotation of the expression "a key" \ "a key"”, designating all other keys, e.g., clefs in music or keys to decode encrypted texts, or controls on mechanical devices.

We will give now several theorems which characterize unambiguous (therefore also ambiguous) expressions with the help of the notions and theorems introduced earlier.

T4. $t$ is unambiguous $\Leftrightarrow \neg \exists t^{\prime} \subseteq t\left[\left(d\left(t \backslash t^{\prime}\right) \neq \emptyset \wedge d\left(t \backslash t^{\prime}\right)=d(t) \backslash d\left(t^{\prime}\right)\right] .{ }^{11}\right.$

A direct conclusion following from Theorem $\mathrm{T} 4$ is

T5. $\forall t^{\prime} \subseteq t\left(d\left(t^{\prime}\right)=d(t)\right) \Rightarrow t$ is unambiguous.

An implication that is converse to T5 is not obviously true. For example, if $t^{\prime}$ is a singleton and has the following inscription as the only token:

10 Let us remind that expressions-types are sets of tokens, hence the difference of two expressions is here one of two sets.

11 The proof of this theorem is given in Appendix. 


\section{laptop}

whose object reference is my own laptop, and the expression $t$ is a set of all inscriptions-tokens identifiable with this inscription (and acknowledged to be an unambiguous expression, according to D6a), then the denotation of subtype $t^{\prime}$ of expression $t$ is not equal to the denotation of expression $t$.

T6. $t$ has an unambiguously assigned meaning $\Rightarrow t$ is unambiguous.

Proof T6 follows directly from D3, T3 and T5.

Thus, the possessing of unambiguously assigned meanings by expressionstypes of language $L$ is a sufficient condition of their unambiguity.

Obviously, it also follows from T6 that ambiguous expressions do not have unambiguously assigned meanings and that language in logical conception should be free from ambiguous expressions.

The condition of unambiguity of expression $t$ is not however a sufficient one for $t$ to have an unambiguously assigned meaning, since when, for example, $t=$ "a book" is an unambiguous expression, in compliance with D6a, then there exists expression-type $t^{\prime}$ = "a book ${ }^{1}$ " which is a set of tokens identifiable with words, whose object reference are books by Jacek Jadacki, such that $t^{\prime} \subset t$ and $d\left(t^{\prime}\right) \neq d(t)$ (because $d\left(t^{\prime}\right) \subset d(t)$ ), whence on the basis of theorem T3 we have $m\left(t^{\prime}\right) \neq m(t)$, and $t$ does not have an unambiguously assigned meaning as it does not satisfy definition D3.

\section{About the Ontological Neutrality of Logic}

This part has a summarizing character. It presents the basic assumptions and results presented in Section 2, aimed at showing the realization of the main objectives of this work.

3.1. Subsections 2.2.1 and 2.2.2 of this work sketch and discuss formal-logic theories of language, which are built in accordance with the logical conception of language. These theories were built over classical logic together with set theory. Theoretical considerations are rather general and extensive. They do not depend on symbolics or notations of expressions of the language being described or concrete grammatical rules.

3.2. Discussing, in Subsection 2.2.1, the theory of language syntax, we pointed to the possibility of building it on two different levels, one of which stems from concretes, language tokens of signs, whereas the other one - from their classes, types of language signs, conceived as abstract beings. 
- The consequence of theoretical considerations was the statement of a complete analogy between syntactic notions of both levels.

- Thus, logic does not settle here which of the views with reference to the nature of language objects: concretistic or idealistic, platonizing, is right.

- Since, however, the both two-aspect theoretical approaches towards language syntax are equivalent, formalizing language for the first time - on the level of concretes, we do not impoverish the resource of theorems of the described language syntax and we can do without postulating the existence of ideal beings that types of language expressions are.

- Hence, there follows the philosophical thesis about the possibility of eliminating assumptions of the existence of ideal beings in considerations pertaining to syntax, as long as these beings are treated as classes of identifiable signstokens (language concretes) ${ }^{12}$.

3.3. By sketching, in Subsection 2.2.2, the semantic-pragmatic theory of language, we showed that:

- a meaning can be assigned to its well-formed expression-types (through function $m$ ),

- these expressions have a meaning (D2),

- a meaning (D3) can unambiguously be assigned to them,

- while being used, they designate some objects (D4),

- they denote (have a denotation), since

- a denotation can be assigned to them (through function $d$ ),

- designated objects belong to the set Ont.

We merely assumed about set Ont of extra-language objects (beings), designated by expressions-types, that it is a non-empty set, penetrating through neither the structure of its beings nor their ontological categorization. Full characteristics of language considered from the ontological point of view and in compliance with its logical Ajdukiewicz's concept, can be described in this formal-logic theory.

For the sake of the description we did not make use of any other existential assumptions, apart from those superimposed in the algebra of sets. Neither when it comes to the existence of language expressions, nor their extra-language counterparts. In this sense we can state that the logic applied here (with the set theory) is ontologically neutral.

12 Formalism leading to this statement, however, is based on the Platonic set theory and is not really ontologically neutral (see note 7) 


\section{Appendix}

We give here proofs of theorems T2 and T4, using the method of natural deduction (assumptive) which was put forward in the work by J. Słupecki and L. Borkowski (1967).

T2. $t=t_{1} \cup t_{2} \wedge t_{1} \subseteq t \wedge t_{2} \subseteq t \Rightarrow d(t)=d\left(t_{1}\right) \cup d\left(t_{2}\right)$.

Proof.

1. $t=t_{1} \cup t_{2}$

2. $t_{1} \subseteq t \wedge t_{2} \subseteq t$

3. $d\left(t_{1}\right) \subseteq d(t) \wedge d\left(t_{2}\right) \subseteq d(t)$

4. $d\left(t_{1}\right) \cup d\left(t_{2}\right) \subseteq d(t)$

1.1. $p \in$ Ont $\wedge p \in d(t)$

1.2. $p \in d\left(t_{1} \cup t_{2}\right)$

1.3. $\exists u \in U \operatorname{User} \exists e \in t_{1} \cup t_{2}(u \operatorname{se}(u, e)=p)$

1.4. $u_{1} \in U \operatorname{User} \wedge\left(e_{1} \in t_{1} \vee e_{1} \in t_{2}\right) \wedge u s e(u 1, e 1)=p$

1.5. $e_{1} \in t_{1} \Rightarrow \exists e \in t_{1} \exists u \in \operatorname{User}(u \operatorname{se}(u, e)=p) \Rightarrow$ $p \in d\left(t_{1}\right) \Rightarrow p \in d\left(t_{1}\right) \cup d\left(t_{2}\right)$

$1.6 e_{1} \in t_{2} \Rightarrow \exists e \in t_{2} \exists u \in \operatorname{User}(u \operatorname{se}(u, e)=p) \Rightarrow$ $p \in d\left(t_{2}\right) \Rightarrow p \in d\left(t_{1}\right) \cup d\left(t_{2}\right)$

1.7. $e_{1} \in t_{1} \vee e_{1} \in t_{2} \Rightarrow p \in d\left(t_{1}\right) \cup d\left(t_{2}\right)$

1.8. $p \in d\left(t_{1}\right) \cup d\left(t_{2}\right)$

5. $p \in$ Ont $\wedge p \in d(t) \Rightarrow p \in d\left(t_{1}\right) \cup d\left(t_{2}\right)$

6. $\forall p \in \operatorname{Ont}\left(p \in d(t) \Rightarrow p \in d\left(t_{1}\right) \cup d\left(t_{2}\right)\right)$

7. $d(t) \subseteq d\left(t_{1}\right) \cup d\left(t_{2}\right)$ $d(t)=d\left(t_{1}\right) \cup d\left(t_{2}\right)$ (additional assumption)

$\{1.2, \mathrm{D} 5, \mathrm{D} 4\}$

$\{1.4, \mathrm{D} 5, \mathrm{D} 4\}$

$\{1.4, \mathrm{D} 5, \mathrm{D} 4\}$

$\{1.5,1.6\}$

$\{1.4,1.7\}$

$\{1.1 \rightarrow 1.8\}$

$\{5\}$

$\{6\}$

$\{4,7\}$ 
T4. $t$ is unambiguous $\Leftrightarrow \neg \exists t^{\prime} \subseteq t\left[\left(d\left(t \backslash t^{\prime}\right) \neq \emptyset \wedge d\left(t \backslash t^{\prime}\right)=d(t) \backslash d\left(t^{\prime}\right)\right]\right.$.

Proof. Proof by contradiction $(\Rightarrow)$.

1. $t$ is unambiguous

\{assum.\}

2. $t_{1} \subseteq t \wedge d\left(t \backslash t_{1}\right) \neq \emptyset \wedge d\left(t \backslash t_{1}\right)=d(t) \backslash d\left(t_{1}\right)$ \{indirect assump.\}

3. $d\left(t_{1}\right) \cap\left(d(t) \backslash d\left(t_{1}\right)\right)=\emptyset$

4. $t_{1} \subseteq t \wedge d\left(t \backslash t_{1}\right) \neq \emptyset \wedge d\left(t_{1}\right) \cap d\left(t \backslash t_{1}\right)=\emptyset$ \{algebra of sets\}

5. $\exists t^{\prime} \subseteq t\left[d\left(t \backslash t^{\prime}\right) \neq \emptyset \wedge d\left(t^{\prime}\right) \cap d\left(t \backslash t^{\prime}\right)=\emptyset\right]$

6. $t$ is not unambiguous contradiction

Proof by contradiction $(\Leftarrow)$.

In the proof, we use the following theorem of algebra of sets:

$\mathrm{T}\left({ }^{\star}\right)$. If $A=A^{\prime} \cup B \wedge A^{\prime} \cap B=\emptyset \wedge A=A^{\prime} \cup C \wedge A^{\prime} \cap C=\emptyset$, then $B=C$.

1. $\neg \exists t^{\prime} \subseteq t\left[\left(d\left(t \backslash t^{\prime}\right) \neq \emptyset \wedge d\left(t \backslash t^{\prime}\right)=d(t) \backslash d\left(t^{\prime}\right)\right]\right.$

\{assum.\}

2. $t$ is not unambiguous \{indirect assump.\}

3. $t_{1} \subseteq t \wedge d\left(t \backslash t_{1}\right) \neq \emptyset \wedge d\left(t_{1}\right) \cap d\left(t \backslash t_{1}\right)=\emptyset$ \{D6a, 2\}

4. $d\left(t_{1}\right) \subseteq d(t) \wedge t=t_{1} \cup\left(t \backslash t_{1}\right)$

5. $\quad d(t)=d\left(t_{1}\right) \cup d\left(t \backslash t_{1}\right) \wedge d\left(t_{1}\right) \cap d\left(t \backslash t_{1}\right)=\emptyset$

6. $d(t)=d\left(t_{1}\right) \cup\left(d(t) \backslash d\left(t_{1}\right)\right) \wedge d\left(t_{1}\right) \cap\left(d(t) \backslash d\left(t_{1}\right)\right)=\emptyset$

7. $d\left(t \backslash t_{1}\right)=d(t) \backslash d\left(t_{1}\right)$

8. $\exists t^{\prime} \subseteq t\left[\left(d\left(t \backslash t^{\prime}\right) \neq \emptyset \wedge d\left(t \backslash t^{\prime}\right)=d(t) \backslash d\left(t^{\prime}\right)\right]\right.$ contradiction

Acknowledgment: The author expresses her sincere gratitude towards the colleagues: Gabriela Besler, Alex Citkin and Zbigniew Bonikowski for their facilitating her an access to source publications and data needed to fill in some gaps in this work.

The author would also like to thank Bartłomiej Skowron - the editor of this volume - and the Referees who offered a number of suggestions which greatly added to improving on this paper.

\section{Bibliography}

Ajdukiewicz, K. (1931). O znaczeniu wyrażeń [On the meaning of expressions]. In The commemorative book of Polish Philosophical Society in Lvov (pp. 31-77).

Ajdukiewicz, K. (1934). Sprache und Sinn. Erkenntnis, 4, 100-138.

Ajdukiewicz, K. (1935). Die syntaktische Konnexität. Studia Philosophica, 1, 1-27. English translation: Syntactic connection in S. McCall (Ed.), Polish logic 1920-1939, pp. 202-231, 1967. Oxford: Clarendon Press. 
Ajdukiewicz, K. (1949-1950). On the notion of existence. Studia Philosophica, vol. IV, 7-22.

Ajdukiewicz, K. (1960). Związki składniowe między członami zdań oznajmujących [Syntactical relations between constituents of declarative sentences]. Studia Filozoficzne, 6(21), 73-86.

Ajdukiewicz, K. (1975). Pragmatic Logic. Synthese Library, vol 62, Dordrecht-Boston-Warsaw: Reidel-PWN.

Augustynek, Z. \& Jadacki, J. J. (1993). Possible ontologies. Amsterdam-Atlanta: Rodopi.

Bocheński, J. M. (1949). On the syntactical categories. New Scholasticism, 23, 257-280.

Bocheński, J. M. (1974). Logic and ontology. Philosophy East and West, 24(3), 275-292.

Carnap, R. (1934). Logische Syntax der Sprache. (Schr.z. wiss. Weltauff), Wien: Springer. English translation: The logical syntax of language, 1937, London and New York: Horcout and Kegan; Reprinted in 2000 and 2001, London: Routledge.

Carnap, R. (1942). Introduction to semantics. Cambridge, MA: Harvard University Press.

Carnap, R. (1947). Meaning and necessity. Chicago: University of Chicago Press.

Frege, G.(1892). Über Sinn und Bedeutung. Zeitschrift für Philosophie und pilosophishe Kritik, 100, 25-50. English translation: On Sinn and Bedeutung, in H. Feigel, \& W. Sellars (Eds.), Readings in philosophical analysis, 1949, New York: Appleton-Century-Crofts, and also in M. Beaney (Ed.), The Frege reader, pp. 151-171, 1997, Oxford: Blackwell.

Husserl, E. (1900). Logische Untersuchungen, vol. I. Halle.

Husserl, E. (1901). Logische Untersuchungen, vol. II. Halle.

Jadacki, J. J. (1992). Change, action, and causality. Dialogue and Humanism, vol. II No. 3, pp. 87-99.

Jadacki, J. J. (1997). Troubles with categorial interpretation of natural language. In R. Murawski \& J. Pogonowski (Eds.). Euphony and logos. Essays in honour of Maria Steffen-Batóg and Tadeusz Batóg. Amsterdam-Atlanta: Rodopi.

Jadacki, J. J. (2003). From the viewpoint of the Lvov-Warsaw School. Amsterdam-Atlanta: Rodopi. Jadacki, J. J. (2011). What semantics is and what purpose it serves. In A. Brożek, J. J. Jadacki \& B. Žarnić (Eds.), Theory of imperatives from different points of view. Warszawa: Wydawnictwo Naukowe Semper.

Leśniewski, S. (1929). Grundzüge eines neuen Systems der Grundlagen der Mathematik. Fundamenta Mathematicae, 14, 1-81.

Leśniewski, S. (1930). Über die Grundlagen der Ontologie. Comptes rendus des séances de la Société des Sciences et des Lettres de Varsovie, Classe II, 23, 111-132.

Peirce, Ch. S. (1906). Prolegomena to an Apology for Pragmaticism. Monist, 16, 492-546.

Peirce, Ch. S. (1931-1935). Hartshorne C., \& Weiss P. (Eds.). Collected papers of Charles Sanders Peirce: Vols. 1-5. Cambridge, MA: Harvard University Press.

Peirce, Ch. S. (1998). The Essential Peirce. Selected Philosophical Writings, vol. 2 (1893-1913), Bloomington and Indianapolis: Indiana University Press. Peirce Edition Project (N. Houser, general Editor).

Pelc, J. (1979). A functional approach to the logical semiotics of natural languages. In Semiotics in Poland 1894-1969 (selected and edited with an introduction by Jerzy Pelc.). Synthese Library, Studies in Epistemology, Logic and Methodology of Science, vol. 119 (pp. 342375). Dordrecht - Boston: PWN - Reidel.

Perzanowski, J. (2012). Towards Combination Metaphysics. In J. Sytnik-Czetwertyński (Ed.), Art of Philosophy. A selection of Jerzy Perzanowski's Works, (pp. 45-67). Frankfurt, Ontos Verlag. (Originally published in 2004.) 
Stupecki, J., Borkowski, L. (1967). Elements of mathematical logic and set theory. In International Series of Monography in Pure and Applied Mathematics. Oxford-New York-Toronto Warsaw: Pergamon Press - PWN.

Suszko, R. (1958). Syntactic structure and semantical reference, Part I. Studia Logica, 8, 213-144.

Suszko, R. (1960). Syntactic structure and semantical reference, Part II. Studia Logica, 9, 63-93.

Suszko, R. (1964). O kategoriach syntaktycznych i denotacjach wyrażeń w językach sformalizowanych [On syntactic categories and denotation of expressions in formalized languages]. In Rozprawy logiczne [Logical dissertations to the memory of Kazimierz Ajdukiewicz] (pp. 193-204). Warsaw: PWN.

Suszko, R. (1968). Ontology in the tractatus of L. Wittgenstein. Notre Dame Journal of Formal Logic, 9, 7-33.

Tarski, A. (1933). Pojęcie prawdy w językach nauk dedukcyjnych. Warszawa: Nakładem Towarzystwa Naukowego Warszawskiego. English translation: The concept of truth in formalized languages. In J. Corcoran (Ed.), Logic, semantics, metamatematics: Papers from 1923 to 1938, 1956. Oxford: Oxford University Press; second edition 1983. Indianapolis, Indiana: Hackett Publishing Company.

Wittgenstein, L. (1953). Philosophical investigations. Oxford: Blackwell. Third edition in 1967, reprinted 1968-1986.

Wybraniec-Skardowska, U. (1988). Logiczne podstawy ontologii składni języka [Logical foundations of ontology of language syntax]. Studia Filozoficzne, No 6-7 (271-272), 263-284.

Wybraniec-Skardowska, U. (1989). On the eliminability of ideal linguistic entities. Studia Logica, 48(4), 587-615.

Wybraniec-Skardowska, U. (1991). Theory of language syntax. Categorial approach. DordrechtBoston-London: Kluwer Academic Publisher.

Wybraniec-Skardowska, U. (2006). On the formalization of classical categorial grammar. In J. J. Jadacki, \& J. Paśniczek (Eds.), The Lvov-Warsaw School - the new generation. In Poznań Studies in the Philosophy of Sciences and Humanities, vol. 89. (pp. 269-288). Amsterdam-New York: Rodopi.

Wybraniec-Skardowska, U. (2007). Meaning and interpretation, Part I. Studia Logica, 85, 105-132.

Wybraniec-Skardowska, U. (2009). On metaknowledge and truth. In D. Makinson, J. Malinowski, \& H. Wanshing (Eds.), Trends in Logic: Towards mathematical philosophy (pp. 319-343). Berlin-Heidelberg: Springer.

Wybraniec-Skardowska, U. (2015). On Language adequacy. Studies in Logic, Grammar and Rhetoric, 40(53), 257-292.

Wybraniec-Skardowska, U. (2017). Logiczna koncepcja języka wobec założeń egzystencjalnych [Logical conception of language towards existential assumptions]. In Myśli o języku, nauce i wartościach. Series two. To Professor Jacek J. Jadacki on his seventieth birthday [Thoughts on language, science and values] (pp. 299-313). Warsaw: Semper. 


\section{Author Index}

Ajdukiewicz K. 4, 5, 9, 10, 14, 22, 23

Augustynek Z. 23

Besler G. 22

Bocheński J. M. 9, 23

Bonikowski Z. 22

Borkowski L. 21, 23

Carnap R. 6, 14, 23

Citkin A. 22

Frege G. 9, 14, 23

Houser N. 23

Husserl E. 10, 23

Jadacki J. J. 7-9, 17, 23
Leśniewski S. 9, 10, 23

Peirce Ch. S. 6, 7, 23

Pelc J. 23

Perzanowski J. 2, 23

Skowron B. 22

Stupecki J. 21, 23

Suszko R. 9, 24

Tarski A. 6, 24

Wittgenstein L. 14, 24

Wybraniec-Skardowska U. 1, 8, 9, 11-13, 17, 24 
